Swarthmore College

Works

$9-1-2008$

\title{
Contrastivism Rather Than Something Else? On The Limits Of Epistemic Contrastivism
}

Peter Baumann

Swarthmore College, pbauman1@swarthmore.edu

Follow this and additional works at: https://works.swarthmore.edu/fac-philosophy

Part of the Philosophy Commons

Let us know how access to these works benefits you

\section{Recommended Citation}

Peter Baumann. (2008). "Contrastivism Rather Than Something Else? On The Limits Of Epistemic Contrastivism". Erkenntnis. Volume 69, Issue 2. 189-200. DOI: 10.1007/s10670-008-9111-4 https://works.swarthmore.edu/fac-philosophy/17

This work is brought to you for free by Swarthmore College Libraries' Works. It has been accepted for inclusion in Philosophy Faculty Works by an authorized administrator of Works. For more information, please contact myworks@swarthmore.edu. 


\title{
Contrastivism rather than Something Else?
}

\section{On the Limits of Epistemic Contrastivism}

\author{
Peter Baumann
}

Erkenntnis 69, 2008, 189-200

\begin{abstract}
One of the most recent trends in epistemology is contrastivism. It can be characterized as the thesis that knowledge is a ternary relation between a subject, a proposition known and a contrast proposition. According to contrastivism, knowledge attributions have the form "S knows that p, rather than q". In this paper I raise several problems for contrastivism: it lacks plausibility for many cases of knowledge, is too relaxed concerning the third relatum, and overlooks a further relativity of the knowledge relation.
\end{abstract}

One of the most recent trends in epistemology is contrastivism (see Sinnott-Armstrong 2004, Schaffer 2005a, Karjalainen / Morton 2003, Johnson 2001 and Blaauw 2004; an early precursor can be found in Dretske 1972; see also a short passage in Swinburne 2001, 34). It can be characterized as the thesis that knowledge is a ternary relation between a subject, a proposition known and a contrast proposition (which is incompatible with the known proposition, and which can consist of a conjunction of propositions). ${ }^{1}$ According to

1 Contrastivism about knowledge can easily be combined with an analoguous contrastivism about justification. 
contrastivism, knowledge attributions have the form "S knows that $\mathrm{p}$, rather than q" (where "rather than q" is, of course, not part of what is claimed to be known here). Here is an example. Jack is eating cheddar cheese which he can distinguish from marmalade but not from gruyère cheese. Hence, he might know that he is eating cheddar cheese rather than marmalade but he does not know and is not in a position to know that he is eating cheddar rather than gruyère. Like contextualism, contrastivism has interesting things to say about epistemic scepticism. Jack might not be able to rule out that he is being deceived by a Cartesian demon into thinking that he is eating cheddar; hence, he cannot know that he is eating cheddar rather than just suffering from Cartesian cheddar illusions. However, he can still know that he is eating cheddar rather than marmalade. Contrastivism is close not just to epistemic contextualism (see, e.g., DeRose 1999) but also to relevant alternatives theories of knowledge (or justification) (see, e.g., Dretske 1970). In contrast, however, to relevant alternatives accounts, contrastivism assumes that knowledge is ternary. And in contrast to contextualism, contrastivism is not wedded to (but could be combined with) the idea that the truth conditions of knowledge attributions can vary with the attributor's contexts. Contrastivism as explained above is neutral with respect to contextualism: It implies neither contextualist theses nor their negations. One could call any noncontextualist version of contrastivism "pure contrastivism" (see, e.g., for this view SinnottArmstrong 2004) and any contextualist version of it "hybrid (contextualist) contrastivism". Some of the problems raised below might find a solution if contrastivism is combinded with contextualism. - In the following I will raise several critical concerns for contrastivism (and include an appendix on contrastivism about beliefs). They point at 
limitations and necessary modifications of contrastivism and are arranged in the order of increasing weight.

\section{Non-contrastive Knowledge}

There are many cases which seem to strongly support a contrastivist account of knowledge (see, e.g., Schaffer 2005a). Perhaps the best case for contrastivism is perceptual knowledge based on discriminatory abilities. Jack can distinguish between dogs and cats but not between dogs and wolves. He sees a dog in front of him (under normal conditions) and thus comes to know that there is a dog in front of him. According to the contrastivist, "Jack knows that there is a dog in front of him" is elliptical for something like "Jack knows that there is a dog in front of him rather than a cat.” One of the greatest advantages of contrastivism is that it can account for the lack of knowledge in cases like Jack's inability to tell dogs from wolves: "Jack does not know that there is a dog in front of him rather than a wolf” is also true, according to the contrastivist. A binary view of knowledge has problems accounting for our opposing tendencies to attribute and deny knowledge that there is a dog to Jack; contrastivism easily resolves the puzzle. The application to the problem of epistemological scepticism is also tempting: Jack can know that it is a dog rather than a cat but he may not know that it is a dog rather than a dog-hallucination brought about by Descartes' evil demon. Contrastivism can, like contextualism, account for both our sceptical and our anti-sceptical views and tendencies. 
Crucial to all this is the idea that a subject might know that $\mathrm{p}$ with respect to some but not all potential contrast propositions. To be sure, the contrastivist does not need to deny the possibility of cases where a subject knows some proposition with respect to all possible contrast propositions. But this would be an extreme case. Contrastivism has its real point when analyzing normal cases where a subject knows that p rather than q but does not know that $\mathrm{p}$ rather than $\mathrm{r}$ (see above). If that were not the case, contrastivism would lose its point and attractiveness (see, e.g., Schaffer 2005a, sec.2; 2005b). This leads to the following plausibility constraint for any contrastivist analysis of knowledge of some type (perception, memory, etc.):

(Specificity) A contrastivist analysis of knowledge of some type is plausible only if there are for a given subject $\mathrm{S}$ a lot of triples of propositions $\mathrm{p}$, $\mathrm{q}$ and $\mathrm{r}$ such that $\mathrm{S}$ knows that $\mathrm{p}$ rather than q but S does not know p rather than $\mathrm{r}$ (where "knows" refers to knowledge of that type).

This condition is vague in so far as it does not indicate a minimal number of such triples of propositions for some person and type of knowledge. However, we do not need to be more specific here. It is already clear only some but not all types of knowledge meet the Specificity-condition: perception for instance. However, other types of knowledge don't meet it.

Take knowledge of obvious mathematical truths, like the simple one that $2+2=4$. Does anyone who knows that know it in contrast to something else? In contrast to what, 
then? To $2+2=5$ (Or $2+2=-.7$ ? Or $3+3=4$ ? Or $12 \times 12=1212$ ?)? There simply does not seem to be a plausible contrast proposition around. The problem is that (Specificity) does not seem to hold for this kind of knowledge. It is hard to imagine, for instance, how there could be two numbers $x$ and $y$ (not equal to 4 ) such that $S$ knows that $2+2=4$ rather than $2+2=x$ but that $S$ does not know that $2+2=4$ rather than $2+2=y$. It would be very interesting to find someone who, e.g., knows that $2+2=4$ rather than $2+2=40$ but who does not know that $2+2=4$ rather than $2+2=5$ ("too close!"). It would be very hard to make sense of such a subject or even to attribute knowledge to her in the first place. It seems that whoever knows that $2+2=4$ knows this rather than $2+2=z$, for any z not equal to $4 .^{2}$

The contrastivist might reply here that this is still compatible with his view: $\mathrm{S}$ knows that p rather than not-p (or rather than any alternative). This, however, is perhaps compatible with the letter but certainly not with the spirit of contrastivism. The prize for this kind of manoeuvre is the rejection of (Specificity) and trivialization. Nobody would deny that one can talk like that but this way of talking would be like an additional wheel spinning in the void. We might as well go back to the binary view of knowledge.

The point above is not restricted to mathematical knowledge. Similar things can be said about basic forms of logical knowledge. To be sure, there are very difficult questions in mathematics or logic with respect to which it might make sense to say that someone knew at a time that this formula is valid rather than that one. However, this manœuvre

2 To be sure, few, if any, subjects are able to grasp all possible contrast propositions to a given, known proposition. For instance, someone might understand that $2+2=5$ but not understand that $2+2=1 / 4$, due to a lack of understanding of fractions (thanks to a referee here). However, that there is such a difference between "accessible" (for the subject) contrast propositions and non-accessible contrast propositions does not at all support the claim that knowledge is contrastive in the first place or that contrast propositions or a subset of them play the role the contrastivist thinks they play. Similar things hold in the case of contrast proposition which either lack a truth value or are false for nonmathematical reasons, like, e.g., "2+2=Julius Caesar". 
won't work for basic and simple cases like knowledge that if p then p, or that everything is identical with itself (what would be the contrast here?). I will not repeat the argument from specificity here but rather shortly mention another case, namely linguistic or conceptual knowledge. What would be a plausible contrast proposition for knowledge that vixen are female foxes? One can suspect that at least some of the classical candidates for aprioricity create this kind of trouble for contrastivism because they don’t meet (Specificity).

All this suggests that not all knowledge is contrastive. More cautiously: Nobody so far has shown (and it does not seem likely) that all types of knowledge admit of contrastivist analyses. To put it more positively: It seems that contrastivism is most plausible and probably only plausible with respect to a particular kind of knowledge: knowledge of propositions which involves the use of discriminatory cognitive abilities. The use of such abilities need not be restricted to one's external environment: Discrimination is also needed when it comes, for instance, to the identification of a particular emotion as sympathy rather than pity. So, why not explicitly restrict contrastivism to cases of discriminatory knowledge?

One might, however, want to propose more radical consequences. ${ }^{3}$ Starting with the assumption that

(A) If some kinds of knowledge are contrastive, then all kinds of knowledge are contrastive

3 Thanks to a referee here. 
one could argue that since some kinds of knowledge (e.g., knowledge based on discriminatory abilities) are contrastive all kinds of knowledge are contrastive. However, given the above point about mathematics, things would rather cut the other way around: Since not all kinds of knowledge are contrastive, none are. This conclusion would, of course, be very bad for the contrastivist. However, since I do not see any good reason to accept $(\mathrm{A})^{4}$, I would rather propose to restrict contrastivist analyses of knowledge in the way indicated above (see also the brief remark in Luper 2012, 56).

\section{Restricted Relata}

The third relatum of contrastivism is a contrast proposition. But why should only contrast propositions be able to fill the third argument place?

Take the following example. Mary is a meteorologist. On her way to work she runs into a friend who asks her whether it will be raining later that day. Both can clearly see dark rain clouds coming up. Mary replies that she hasn't been to the weather lab yet but that she would certainly expect rain later that day. Let us assume that it does indeed rain later that day. In an ordinary context it then seems true to say of Mary that she knows that it is going to rain later that day. One hour later, however, a colleague at the weather lab asks her whether she already knew whether it was going to rain later that day. Not having finished the usual checks required for the daily weather report, she denies that. In a

4 There are all kinds of differences between the kinds of epistemic states we call "knowledge": e.g., some kinds of "knowledge" preserve information (memory), others involve the acquisition of new information (perception). Why shouldn't there be some kinds of the epistemic states we call "knowledge” which are contrastive while others aren't? 
meteorological context it seems false to say of Mary that she knows that it is going to rain later that day.

How should one analyse this in terms of contrast propositions? To be sure, Mary might know that it is going to rain rather than snow but not know that it is going to rain rather than drizzle. But that is besides the point of our example: What varies in the example above is not the contrast proposition but something else: standards relevant in particular contexts (meteorological contexts, non-work contexts, etc.; see my forthcominga). ${ }^{5}$ One can account for all this by proposing that knowledge is a ternary relation between a subject, a known proposition and, third, some out of a bunch of entities: contrast propositions, context-specific epistemic standards, practical interests (how important is it to get it right?), etc. ${ }^{6}$ This is, I think, still compatible with the contrastivist spirit even if not with its letter as it has been developed so far. It would be compatible with the spirit of contrastivism if one were to generalize the account and open the third argument slot up for many different kinds of things, or, at least, for more things than just contrast propositions.

At the same time, contrastivism would lose some of its simplicity and elegance.

5 To be sure, Mary might know that it is going to rain rather than drizzle only given lab standards but she might know that it is going to rain rather than snow also given lay standards. The point above, however, is a different one: that she might know that $\mathrm{p}$ (it is going to rain), rather than $\mathrm{q}$ (it is not going to rain) according to some standards (relevant in non-work contexts) but not according to some other standards (relevant in lab contexts). Hence, there is more to take into account for the evaluation of knowledge attributions than contrast propositions.

6 The third argument slot would take n-tuples of entities of different kinds (standards, interests, contrasts, etc.) as its argument. The number of entities might vary from case to case: sometimes only a contrast proposition, sometimes only a standard, sometimes both, etc. An alternative way to go about would be to admit $n$ additional argument places (where the value of "n" can, of course, vary; see above). This difference does not matter here. - To indicate what kinds of entities could go into the third slot would be a follow-up task for the contrastivist; I cannot go any deeper into that here. Suffice it to say that, again (see fn. 4), there is no threat of theoretical disunity if one admits that the third argument slot has a disjunctive form. If there were such a threat and if knowledge could therefore not be "disjunctive" in the way indicated, then the argument in this section would be even more critical for contrastivism because it would suggest that contrastivism has unacceptable implications (that it cannot account for the unity of knowledge). 


\section{More Relativization}

In the last section I proposed to broaden contrastivism with respect to admissible kinds of third relata while in the first section I proposed to restrict it with respect to kinds of knowledge. Now, I am going to argue that the contrastivist should accept a further condition on the knowledge-relation, a further relativization. Here is what I have in mind.

Consider Sue who cannot distinguish between a terrier and a dachshund even though she clearly sees a difference between a terrier and a cat as well as between a dachshund and a cat. She also sees a difference between a dachshund and a labrador or between a terrier and a collie; it is just the small dogs which give her epistemic trouble. According to the standard contrastivist view, Sue might well know on one occasion that there is a dachshund in front of her rather than a cat and she might also know on another occasion that there is a terrier in front of her rather than a cat - even though she cannot tell dachshunds from terriers and thus cannot know whether there is a dachshund in front of her rather than a terrier. This, however, sounds abominable and incorrect. It seems false to say that she knows out of the contrast class [dachshund; cat] that there is a dachshund.

What is wrong with such attributions of knowledge? Here is a first rough idea which will have to be developed and modified step by step. Consider Sue, again, who cannot (under any circumstances) distinguish between a dachshund and a terrier. To say that Sue knows that there is a dachshund rather than a cat seems to imply that she can identify dachshunds as such (at least in contrast to, say, terriers) and refer to dachshunds as such. It 
seems to imply that she also knows that there is a dachshund rather than a terrier. If she does not know the latter, then it would rather be correct to say something like "She knows that there is a small dog rather than a cat" but not "She knows that there is a dachshund rather than a cat.”

This suggests that there is a further condition concerning the propositions involved in the knowledge relation. Suppose S cannot distinguish between Fs and Gs (e.g., dogs and wolves). Then there are pairs of propositions $p$ containing F ("F-propositions"; e.g., There is a dog) and $r$ containing $G$ (“G-propositions”: e.g., There is a wolf) such that

replacing $F$ by $G$ at one or more places in $p$ gives us $r$ and $\mathrm{S}$ does not know that p rather than $\mathrm{r}$, and only because $\mathrm{S}$ cannot distinguish between Fs and Gs. ${ }^{7}$

Let us call each member of such a pair of propositions a "defeating proposition" of the other member of the pair. We can now generalize the point made above in a very preliminary way:

(Distinguish-a) If someone knows that p rather than q, then there is no defeating proposition $r$ for $p$.

7 This excludes cases like the following: $\mathrm{S}$ does not know that Fa rather than Ga, where "F" stands for " $\mathrm{x}$ is a dog and Goldbach's conjecture is true" and " $\mathrm{G}$ " for " $\mathrm{x}$ is a cat and Goldbach's conjecture is true". 
In our case above, Sue cannot distinguish between dachshunds and terriers and thus does not know that there is a dachshund in front of her rather than a terrier; thus she does not know that there is a dachshund in front of her rather than a cat. There is a defeating proposition (that there is a terrier).

What we can still say about Sue is this:

(1) Sue knows that there is a dachshund or another kind of small dog rather than a cat.

For reasons analogous to the ones above, we also have to introduce a further condition concerning the contrast proposition. Suppose Sue cannot distinguish (under any circumstances) between cats and mountain lions. We should then say something like this about her:

(2) Sue knows that there is a dachshund or another kind of small dog rather than a cat or another four-legged furry animal indistinguishable from it.

We thus have to add a complement to (Distinguish-a) relating to the contrast proposition instead of the known proposition. Since the contrast proposition is not known, we have to add a slightly different kind of condition here.

Suppose that S cannot distinguish between Hs and Ks (e.g., cats and mountain lions). Then there are pairs of contrast propositions $q$ containing $H$ ("H-propositions"; e.g., There is a cat) and s containing $K$ ("K-propositions": e.g., There is a mountain lion) such that 
replacing $H$ by $K$ at one or more places in $q$ gives us $s$ and

S cannot tell whether q or s, and only because S cannot distinguish between Hs and Ks.

Let us call each member of such a pair of propositions an "undermining proposition" of the other member of the pair. Again, we can say in a very preliminary way:

(Distinguish-b) If someone knows that p rather than $\mathrm{q}$, then there is no undermining proposition $s$ for $q$.

If Sue cannot distinguish between cats and mountain lions and thus cannot tell whether there is a cat or a mountain lion in front of her, then she does not know that there is a dog in front of her rather than a cat. There is an undermining proposition (that is is a mountain lion).

Putting (Distinguish-a) and (Distinguish-b) together, we get

(Distinguish*) If S knows that p rather than q, then there are no defeating propositions $r$ for $p$ and no undermining propositions $s$ for $q .^{8}$

8 Since this is not a definition of "knowledge", there is no bad infinite regress looming here. - One could also put the point like this: If there is such a proposition $r$ or $s$, then the correct knowledge ascription has the form of "S knows that (p or r) rather than q" or "S knows that p rather than (q or s)" or "S knows that (p or r) rather than (q or s)". 
There is, however, a huge fly in the ointment: What if $r$ is a sceptical hypothesis? ${ }^{9}$ By the very nature of a sceptical hypothesis, we can in principle not distinguish between an ordinary scenario (p) and a sceptical one (r). The contrastivist wants to say that we don't know that p rather than r. Given (Distinguish*), we would then have to accept that we don't know that $\mathrm{p}$ rather than $\mathrm{q}-$ for any ordinary propositions $p$ and $q$. This is unacceptable to the contrastivist. An analogous point can be made about the contrast proposition and some sceptical undermining proposition. What then can the contrastivist do about this?

Insofar as (Distinguish*) seems to go into the right direction, we should not give it up but rather introduce a further restriction. Not only do we have to think about potentially defeating or undermining propositions (r, s) but also about what would admit into the group of potentially defeating or undermining propositions. In a sceptical "mood” we let sceptical propositions into this group, in a non-sceptical mood we don’t. What belongs into the classes $(|\mathrm{R},| \mathrm{S})$ of potentially defeating or undermining propositions can vary from situation to situation. Knowledge is relative not just to contrast propositions or classes thereof but also to classes of potentially defeating or undermining propositions. This does not only concern traditional sceptical propositions but all kinds of propositions the subject cannot rule out. Hence, we have to modify (Distinguish*) in the following way:

$9 \quad$ This includes traditional sceptical hypotheses like the evil demon-hypothesis as well as more ordinary hypotheses, like the hypothesis that it is not real cheddar one is eating but something that just looks and smells like it. 
(Distinguish) If S knows that p rather than $\mathrm{q}$, then the classes of potentially defeating or undermining propositions are restricted in such a way that there are no defeating propositions $r$ for $p$ and no undermining propositions $s$ for $q$.

This condition thus forces the contrastivist to also relativize to $\mid \mathrm{R}$ and $\mid \mathrm{S}$, not just to contrast propositions. ${ }^{10}$ That this further relativization is quite valuable and important becomes clearer if we look at cases. Consider Sue, again, who cannot tell dachshunds from terriers but can tell them from labradors and collies. Contrast her with Jack who is unable to tell any kind of dog from any other kind. Both can tell dogs from cats. Suppose they are both confronted with a terrier. We might, given normal circumstances, be entitled to say about both that they know there is a terrier in front of them rather than a cat. However, while "Jack knows that there is a terrier rather than a cat" is true only if "It is a labrador" is excluded from |R, "Sue knows that there is a terrier rather than a cat" is still true if "It is a labrador" is included in |R (but not if, say, "It is a dachshund" is included). And if "It is a labrador” is included in $\mid \mathrm{R}$ both in Sue's and in Jack's case, then it is true to say of Sue but false to say of Jack that they know that there is a terrier in front of them rather than a cat. Hence, the further relativization to the classes $\mid \mathrm{R}$ (and $\mid \mathrm{S}$ ) in Sue's and in Jack's case is needed for a full explanation of the truth conditions of the corresponding knowledge attributions. $^{11}$

$10 \quad \mid \mathrm{R}$ and $\mid \mathrm{S}$ are not included in the set of contrast propositions. Suppose Sue knows that there is a dog rather than a cat. There is just one contrast proposition, namely that there is a cat. The propositions that there is a dachshund or that there is a mountain lion belong into $\mid \mathrm{R}$ and $\mid \mathrm{S}$ respectively.

11 Given that $\mid \mathrm{R}$ is not empty, all this also amounts to a holistic condition on knowledge: In order to know that $\mathrm{p}$ rather than $\mathrm{q}, \mathrm{S}$ also needs to know that $\mathrm{p}$ rather than $\mathrm{r}$ (for a number of instantiations of "r"). 
What determines $\mid \mathrm{R}$ and $\mid \mathrm{S}$ ? It is tempting to give a contextualist answer here. In that case, contrastivism would have to be combined with contextualism. This also goes some way towards explaining the initial phenomenon: that it seems false to attribute knowledge to Sue that there is a dachshund in front of her rather than a cat. If "There is a terrier" is included in $\mid \mathrm{R}$, then Sue violates (Distinguish) and the corresponding knowledge attribution is false. What if only “There is a dachshund” is included in |R? Isn't it then correct to say that she knows that there is a dachshund rather than a cat? Yes but in many if not most or all contexts we would not want to restrict $\mid \mathrm{R}$ in this way. In these contexts, such a restriction seems inadmissible; the context puts a constraint on admissible restrictions of $\mid \mathrm{R}$ (similar things hold of $\mid \mathrm{S}$, of course). In most normal contexts we would not be willing to restrict |R in such a way that, say, "Sue knows there is a dachshund born in 2002 and from North-East Switzerland rather than a cat” comes out true. This is not to say that there could never be any contexts where we would make this restriction. The Swiss association of dachshund owners might test their member's expertise at their annual meeting by asking them to determine age and origin of the dachshunds at the meeting. And some members might be able to tell whether a given dachshund was born in 2002 or some other year, etc.

Finally, a worry: Doesn’t (Distinguish) clash with (Specificity) (sec. 1)? Doesn’t the latter allow for something the former excludes, namely that $\mathrm{S}$ knows that $\mathrm{p}$ rather than $\mathrm{q}$ while not knowing that $\mathrm{p}$ rather than $\mathrm{r}$ ? No. When we say that $\mathrm{S}$ knows that $\mathrm{p}$ rather than $\mathrm{q}$, we are excluding any proposition like $r$ from $\mid$ R. However, we are not thereby denying that there are such propositions (like $r$ ) - whose existence is demanded by (Specificity). The 
appearance of a clash between (Distinguish) and (Specifity) might well be due to not explicitly relativizing to the restricted class $\mid \mathrm{R}$.

The contrastivist can stick to the ternary analysis of knowledge but will have to add the further relativization to classes of defeating and undermining propositions in order to keep her view plausible. The prize to pay for this is a remarkable loss of simplicity (and elegance). ${ }^{12}$ Apart from that, the contrastivist will have to explain why some choices of such classes seem inadmissible. A contextualist story seems needed here. This would make contrastivism “impure”.

\section{Conclusion}

Contrastivism is, I have argued, plausible only for certain types of knowledge (section 1);

it has a narrower scope than its proponents seem to expect. Furthermore, the third relatum of the knowledge relation cannot be restricted to contrast propositions (section 2); acknowledging this makes contrastivism lose some of its characteristic profile. Apart from that, additional relativization and contextual constraints concerning admissible

propositions complicate the picture considerably (section 3). ${ }^{13}$ To be sure, not even in

12 Perhaps there is also a loss of fit with the empirical data concerning ordinary ways of talking and thinking about knowledge. However, the two additional relativizations result from theoretical constraints within contrastivism (see above). If a lack of fit with certain kinds of data results and if that is a problem, then all the worse for contrastivism.

13 Some authors (see Hawthorne 2004, p. 29; Stanley 2005, p. 9) hold that acceptable practical reasoning requires knowledge of its premises. Whatever the connection between knowledge and practical reasoning should turn out to be, if there is one at all, then contrastivists about knowledge will also have to tell a corresponding contrastivist story about practical reasoning (see Sinnott-Armstrong 2004, 2006). This project, however, is problematic for reasons I cannot go into here (but cf. my forthcoming-b for related problems concerning moral reasoning). 
conjunction do these points "refute" contrastivism. However, they point at limitations of the theory and at certain prizes it has to pay if it wants to retain plausibility. 


\section{Appendix: Contrastive Beliefs?}

What about contrastivism about beliefs ${ }^{14}$ ? If belief is contrastive, then perhaps knowledge derives its contrastive nature from belief ${ }^{15}$ The thesis would be that belief, too, is a ternary relation between a subject, a proposition believed and a contrast proposition. Sentences of the form "S believes that p" would be elliptical for sentences of the form "S believes that p rather than q" (where "rather than q" is, of course, not part of the content of the belief). Sue might believe that she is seeing a dog rather than that she is seeing a cat but she might not believe that she is seeing a dog rather than that she is seeing a wolf. Is this unorthodox view about the nature of belief plausible?

Let us start with the uncontroversial idea that an acceptable account of belief must allow for an account of the truth conditions of beliefs. If one thinks of beliefs in the usual way - as a dyadic relation between a person and a proposition -, then it is easy to give truth conditions for beliefs. It works according to the following schema:

The belief that $\mathrm{p}$ is true iff $\mathrm{p}$.

14 Schaffer 2005, sec. 4 seems to assume that belief is contrastive; however, in personal communication he has denied this. Swinburne 2001, 34 very shortly remarks that belief is contrastive but does not go into details. Much more detailed is Blaauw 2004, ch.6, and recently Morton/ Karjalainen 2008, 278279).

15 I am not assuming the false principle here that if $F$ is $L$ and $F$ is necessary for $G$, then $G$ is $L$. If knowledge should inherit its contrastive nature from belief, then the inheritance would have to be based on something else than the mere fact that belief is necessary for knowledge. 
There is a principle at work here which is analogous to disquotation principles for sentences: Skip "the belief that" on the left side of "is true iff" and you get the right hand side of the bi-conditional (assuming that the meta-language contains the object-language). How does this work in the case of contrastive belief? One might think of something like the following schema:

The belief that $\mathrm{p}$ rather than $\mathrm{q}$ is true iff $\mathrm{p}$ rather than $\mathrm{q}$.

A principle resembling the above “disquotation” principle has been used but now with a weird result: We don't understand what kind of condition that is and what the right-hand side of the conditional means. What does it mean to say that "p rather than q"? One way to go would be to extend contrastivism to truth. Truth would be contrastive insofar as truth conditions (for sentences, beliefs, etc.) are themselves contrastive. I wouldn’t choose this option: It is hard if not impossible to make any sense of this idea. Apart from all that ,"rather than q" is not part of the content of the belief and for that reason one might not want to include it in the "disquotation".

Perhaps we need to modify the disquotation principle for contrastive belief in the following way:

The belief that $p$ rather than $q$ is true iff $p$. 
But this also leads to several problems: The belief that $\mathrm{p}$ rather than $\mathrm{q}$ would have the same truth conditions as the belief that $\mathrm{p}$ rather than $\mathrm{r} .{ }^{16}$ The belief that the book is red rather than blue would have the same truth conditions as the belief that the book is red rather than yellow. How could these two beliefs have the same truth conditions if they are substantially different beliefs? I am not suggesting that truth conditions alone individuate beliefs. Rather, I am suggesting that quite different beliefs should not be expected to share their truth conditions.

There is also another problem. It seems possible that S has two beliefs:

The belief that $\mathrm{p}$ rather than $\mathrm{q}$

and

The belief that q rather than $r$,

such that "p" and "q" cannot, of course, both be true.

Here is an example:

Fred believes that Jack stole the bike (p) rather than Jill stole the bike (q),

But it is also the case that

16 Thanks to RC here. 
Fred believes that Jill stole the bike (q) rather than Jill stole the car (r).

Let us assume here that only one theft has occurred. What would be the truth conditions of these two beliefs according to the modified disquotation principle? The first belief is true iff $\mathrm{p}$ whereas the second belief is true iff q. So far, so good, one might say. But really, so far so bad: $p$ and $q$ cannot both be true because $q$ is a contrast proposition for $p$. On the other hand, the two beliefs do not seem contradictory or mutually inconsistent. But how can their truth conditions then be mutually incompatible?

The overall conclusion is clear: Even if you are a contrastivist about knowledge you shouldn't be a contrastivist about belief. 


\section{References}

Author forthcoming-a, Contextualism and the Factivity Problem, in: Philosophy and Phenomenological Research.

Author forthcoming-b, Some Problems for Moral Contrastivism. Comments on SinnottArmstrong, in: Philosophical Quarterly.

Blaauw, Martijn 2004, Contrastivism: Reconciling Skeptical Doubt with Ordinary Knowledge, Ms.

DeRose, Keith 1999, Contextualism: An Explanation and Defense, in: John Greco/ Ernest Sosa (eds.), The Blackwell Guide to Epistemology, Oxford: Blackwell, 187205.

Dretske, Fred 1970, Epistemic Operators, in: Journal of Philosophy 67, 1007-1022.

Dretske, Fred 1972, Contrastive Statements, in: Philosophical Review 81, 411-437.

Hawthorne, John 2004, Knowledge and Lotteries, Oxford: Oxford University Press.

Johnson, Bredo C. 2001, Contextualist Swords, Skeptical plowshares, in: Philosophy and Phenomenological Research 62, 385-406.

Karjalainen, Antti /Morton, Adam 2003, Contrastive Knowledge, in: Philosophical Explorations 6(2), 74-89.

Luper, Steven 2012, Contrastivism and Skepticism, in: International Journal for the Study of Skepticism 2, 51-58. 
Morton, Adam/ Karjalainen, Antti 2008, Contrastivity and Indistinguishability, in: Social Epistemology 22, 271-280.

Schaffer, Jonathan 2005a, Contrastive Knowledge, in: Tamar Szabó Gendler \& John Hawthorne (eds.), Oxford Studies in Epistemology, vol.1, 235-271.

Schaffer, Jonathan 2005b, What Shifts? Thresholds, Standards, or Alternatives?, in: Gerhard Preyer \& Georg Peter (eds.), Contextualism in Philosophy, Knowledge, Meaning, and Truth, Oxford: Clarendon, 115-130.

Sinnott-Armstrong, Walter 2004, Classy Pyrrhonism, in: Walter Sinnott-Arnstrong (ed.), Pyrrhonian Skepticism, Oxford: Oxford University Press, 188-207.

Sinnott-Armstrong, Walter 2006, Moral Skepticisms, Oxford: Oxford University Press.

Stanley, Jason 2005, Knowledge and Practical Interests, Oxford: Oxford University Press.

Swinburne, Richard 2001, Epistemic Justification, Oxford: Clarendon. 